International Journal of Dental Research, 6(1) (2018) 1-2
International Journal of Dental Research
Website: $\begin{gathered}w w \text {. sciencepubco.com/index.php/IJDR } \\ \text { doi: } 10.14419 / \text { ijdr.v6il.8188 } \\ \text { Research paper }\end{gathered}$
RPC

\title{
Balloon inflation impression technique
}

\author{
Bazanth Yahiya.M ${ }^{1}$, Dennis Paul ${ }^{2}$, Faizal C.Peedikayil ${ }^{2}$ \\ ${ }^{1}$ Post graduate student, Dept of Pedodontics \& Preventive Dentistry, Kannur Dental College, Kerala, India \\ ${ }^{2}$ Head of Department, Dept of Pedodontics \& Preventive Dentistry, Kannur Dental College, Kerala, India \\ *Corresponding author E-mail: bazanthyahiya.mailme@gmail.com
}

\begin{abstract}
Background: Impression recording can become a challenging procedure in a patient with high arch palate and cases with altered palatal morphology.

Method: A stock tray is modified with a hole in the center corresponding to the rubber tube diameter of a sphygmomanometer. Tube is inserted into the hole with a vinyl glove fastened to it with the help of rubber bands or cyanoacrylate. Minimal amount of additional polysilicon material is loaded on to the tray, and assembly is carried into patient's mouth. Vinyl Gloves are inflated, and knob is locked. Tray is kept in a position till the material sets, and the whole assembly is removed with caution.

Result: This innovative impression recording technique showed better recording of impression in cases with high palatal vault.

Conclusion: This impression procedure is an alternative to the traditional impression recording procedure to yield better treatment results in patients with anatomical variations.
\end{abstract}

Keywords: Additional Polysilicon; Higharch Palate; Sphygmomanometer, Vinyl Glove

\section{Introduction}

Dental impression recording is a frequent procedure in dentistry. Success of any orthodontic appliance or prosthesis depends on the definitiveness of the impression recorded. Impression making in certain occasions can pose a challenge to the clinician and maybe a fatiguing procedure for the patients. Such situations are mainly encountered in patients with high arched palate and other altered palatal morphology, which are associated with various syndromes. A high-arched palate or a high-vaulted palate is where the palate is unusually high and narrow. It is usually a developmental feature that may occur in isolation or in association with a number of conditions. It can also be an acquired condition caused by chronic thumb-sucking (Gorlin et al .2001, p.977, Yokota et al .2007, p.57) Syndromes, which may be associated with the high-arched palate include: Crouzon syndrome, Down syndrome Apert syndrome, Treacher Collins syndrome, Marfan syndrome, Incontinentia pigmenti etc. (Saraf 2006, p.547) This situation demands a modification of conventional impression recording as the high palatal vault shape has to be recorded. Tradition impressions mostly do not record the details because of the altered morphology and in turn affect the retention of the appliance or prosthesis (Gupta 2016, p.311).

An innovative impression technique using balloon is discussed, which is mainly indicated in high arch palate and other altered morphology associated with various syndromes.

\section{Method}

\subsection{Armamentarium}

- Modified stock tray with a hole in the center.

- Sphygmomanometer bulb with rubber tube attached to it.
- Cyanoacrylate or rubber bands.

- Vinyl glove.

- Additional polysilicon impression material.

A stock tray was modified with a hole in the center of the palatal aspect with a diameter corresponding to the tube diameter of a clinical sphygmomanometer. A piece of a vinyl gloves was secured on to the outlet of a clinical sphygmomanometer tube and bulb with the aid of cyanoacrylate or rubber bands. This assembly of a rubber tube with a vinyl gloves was then squeezed into the hole (Fig 1).

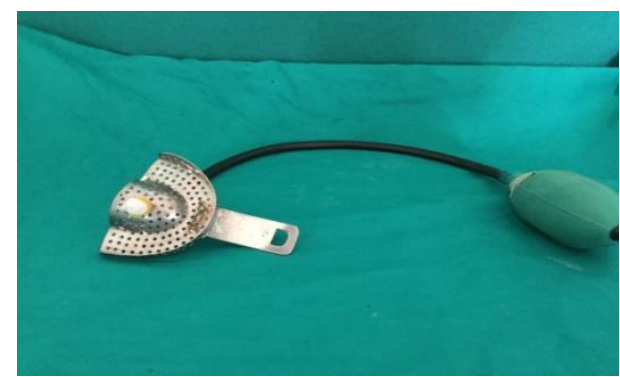

Fig. 1: Customized Balloon Impression Tray.

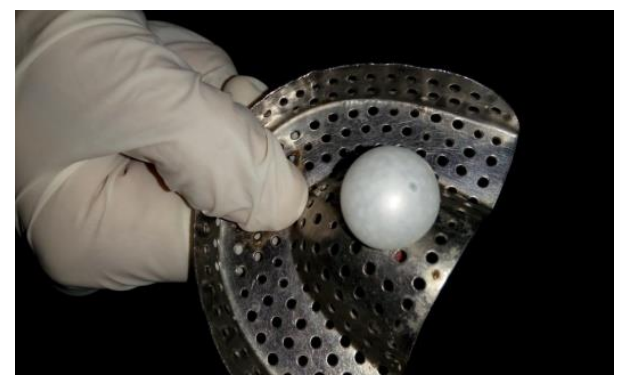

Fig 2: It Customized Balloon Impression Tray with Inflated Balloon. 
Before placing it in a patient's mouth, the assembly was checked by inflating the vinyl glove and locking the knob of the bulb to ensure there was no efflux of air (fig II). This prepared tray assembly was then equipped to record the impression. Minimal amount of additional poly silicon material adequate enough to partly cover the palatal aspect of a tray was loaded on to it. The whole assembly was then carried into patient's mouth and positioned without applying any pressure.

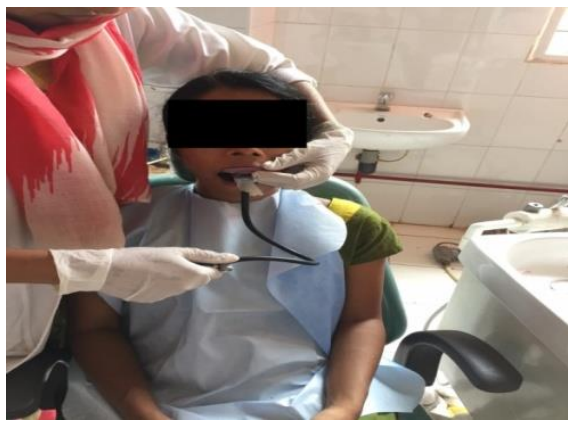

Fig 3: Impression Recording.

The glove is then distended with the help of sphygmomanometer bulb (Fig: III) Out flow of air is prevented by locking the knob of the bulb. The glove was distended till the patient expressed a feeling of expanding glove against the palate. Pressure was maintained till the material sets. Up on setting of the impression material, air was drained up by unlocking the knob of the sphygmomanometer which assists in easy removal of the impression from patient's mouth. (Fig:IV). Impression was then disinfected for cast fabrication.

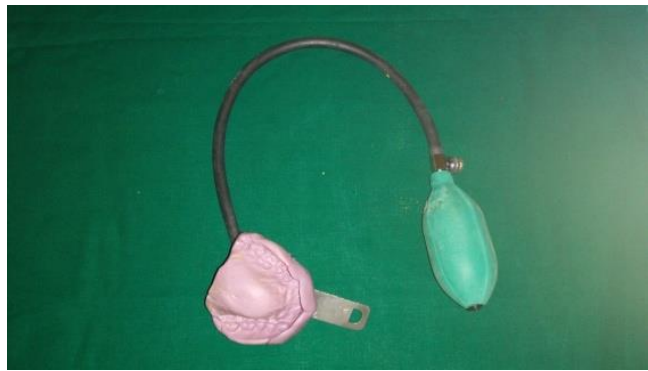

Fig. 5: Recorded Maxillary Impression.

\section{Discussion}

An accurate impression is critical to ensure good appliance fit. Many factors that are critical for an accurate impression are the selection of proper impression trays and appropriate selection of impression material. Making an impression for a patient with limited mouth opening or high palatal vault is challenged to a dental surgeon because of the patient's clinical condition and difficulties encountered in impression making. Stock trays which are available will not be able to record the anatomic variations in the patient with high arch palate or palatal malformations (Saraf 2006, p.547) Conventional method for recording high palatal vault includes placing impression material on to the palate prior to the placement of a loaded impression tray into the patient's mouth. Various alternative techniques with certain modifications from the conventional techniques are routinely made by the clinician overcome various bottle necks associated with a conventional technique.

The balloon impression technique described here is simple to perform and is cost effective. The impressions can be made using the stock tray itself with certain modifications. The main drawbacks of Balloon impression technique include more studies are required to ensure the dimensional stability of an impression recorded with this technique and moreover, pressure experienced by the patient against the palate is subjective. Variations can occur, which depends up on the tactile sensation of the patient.
Various impression materials can be used to record the impressions in patients with a high palate. Elastomeric Impression materials are generally advised for patients with palatal malformations since they are easily moldable, sufficiently hard, stable to support during an impression. Moreover, the elastomeric material gives an accurate impression and is flexible enough to remove from the mouth after disassembling (Hamalian et al. 1992, p.153)

\section{Conclusion}

Conventional impression recording technique demands certain modifications at least in some clinical scenarios for better treatment outcome. This innovative impression procedure is an alternative to the traditional impression recording procedure to yield better treatment results in patients with anatomical variations.

\section{Acknowledgement}

We would like to show our gratitude to Dr.Chandru, Dr.Soni, Dr.Dhanesh, Dr.Deepak, Dr.Shahabas, Dr.Raneem and Dr.Shaheen for their inputs.

\section{References}

[1] Gorlin, R J; Cohen M M; Hennekam, R C M. 2001. Syndromes with unusual facies: well-known syndromes. Syndromes of the head and neck. (4th ed.). New York: Oxford University Press.9771038

[2] Yokota R, Mishiro M, Abe T, et al.2007. Pressure on anterior region of palate during thumb-sucking.Bull Tokyo Dent Coll; 48 (2):57-66. https://doi.org/10.2209/tdcpublication.48.57.

[3] Saraf S.2006. Features of syndromes and conditions affecting oral and extra oral structures.Textbook of oral pathology.Jaypee Brothers Medical Publishers Ltd. New Delhi: 547-54.

[4] Gupta L.2016. Pneumatic impression: Improving dental arch impression with an inflatable balloon.J Indian Prosthodont Soc; $16(3): 311-4$

[5] Hamalian TA, Nasr E, Chidiac JJ.2011. Impression materials in fixed prosthodontics:influence of choice on clinical procedure.J Prosthodont; 20 (2): 153-60. https://doi.org/10.1111/j.1532849X.2010.00673.x. 